Copyright (@ 2009 Institute of Electrical and electronics Engineers, Inc.

All Rights reserved.

Personal use of this material, including one hard copy reproduction, is permitted.

Permission to reprint, republish and/or distribute this material in whole or in part for any other purposes must be obtained from the IEEE.

For information on obtaining permission, send an e-mail message to stds-igr@ieee.org.

By choosing to view this document, you agree to all provisions of the copyright laws protecting it.

Individual documents posted on this site may carry slightly different copyright restrictions.

For specific document information, check the copyright notice at the beginning of each document. 


\title{
Sensitivity Based Procedures for Short Term Augmentation of Transmission System in Restructured Electricity Market
}

\author{
M. R. Hesamzadeh, Student Member IEEE, N. Hosseinzadeh, Member IEEE, and \\ P. J. Wolfs, Senior Member IEEE
}

\begin{abstract}
Transmission network was recognized as natural monopoly and almost everywhere subject to some kind of regulation in a restructured electricity market. The role of the transmission system is to provide an indiscriminate access for all market players along with an acceptable level of reliability and security. Regulating authorities have to decide about the augmentation investment. As an on going research on forming a robust algorithm for the expansion planning of transmission system in Queensland State, Australia, this paper presents two procedures for the quasi-optimal short-term augmentation of the transmission system.
\end{abstract}

The proposed approaches can accommodate (1) Security of the power delivery to the load points of the transmission system in terms of single line outages (2) Minimization of the transmission system lost load (3) Providing full competitive electricity market for market participants (4) Construction and maintenance costs of transmission augmentation options and (5) Operation efficiency of the transmission grid in their planning frameworks.

Each expansion option of the transmission system is evaluated by the aforementioned criteria through designation of a set of indices. The proposed procedures benefits from the concepts of the sensitivity analysis and dynamic programming as well as aggregation method, weighted sum function, in their multicriteria decision making.

The introduced procedures are very promising in case of short term expansion planning of the transmission system. Considering the sensitivity analysis concept employed, in case of long term planning the method is appreciable in smart detection of the suitable zones for expansion. The procedures would be very useful in case of large scale power systems.

A 6 bus test system and modified IEEE 30 bus test system are used to validate the effectiveness of the proposed procedures.

Index Terms-Transmission Planning, Sensitivity Analysis, Dynamic Programming, Linear Programming, Reliability, Security, Electricity Market

\section{INTRODUCTION}

$\mathrm{T}_{\mathrm{a}}^{\mathrm{H}}$ HE liberalization of the electricity market and the accompanying breakup of formerly vertically integrated companies into different independent enterprises have faced the power-network planner to the new tasks and objectives in the planning of their network. Transmission system as the major part of the electricity market is not exempt of the extreme changes in the operation and planning criteria. Transmission system providers have their own planning criteria in serving distribution companies and large loads connected to the transmission grid. These criteria are so variable and range from voltage stability issues in the
Queensland Transmission Grid, Australia [1] to the Market based issues in California electricity market [2].

However, in-depth analyzing of the transmission planning procedures all over the world can reveal many common points which have been addressed through most of the implemented schemes.

Although a variety of approaches have been proposed to plan a transmission network in a traditional and restructured electricity industry [3], it is still necessary to find appropriate methods for the expansion planning of transmission systems considering the requirements of independent transmission companies operating in different electricity markets. The research publications on this area fall into two broad categories, namely,

A. Adapting prevailing tools for expansion planning of the transmission system in competitive electricity market [4],[5] and,

B. Developing new tools for addressing new issues in expansion planning of the transmission system in the new competitive environment [6], [7].

As a categorized research in part A, this paper proposes two procedures for multi criteria and short term expansion planning in the restructured electricity market.

Transmission System Adequacy Index (TSAI), Transmission System Security Index (TSSI), Transmission System Operating Efficiency Index (TSEI), and Electricity Market Efficiency Index (EMEI) are proposed for the evaluation of each expansion option. Option Performance Index (OPI) is used as a weighted aggregation for final scoring of each option.

Using the introduced indices, first approach takes a step by step scheme for addition of the most effective options while the second approach removes the options from the populated transmission system. In both schemes, the state of transmission system and electricity market are measured dynamically based on the introduced indicators. Investment budget and/or OPI can be used as a criterion for stopping the expansion. Based on this criterion, the expansion of the transmission system is stopped when there is not a satisfying change in state of transmission system and electricity market.

The proposed procedures can successfully locate the quasi optimum topology of the transmission system in a forward and backward predictive framework.

On the other hand, smart reduction of the search space for long term planning, especially in the case of large scale power systems can be addressed by the proposed set of indices.

In this case, the geographical area of the transmission system is divided into different zones based on the proposed set of sensitivity indices, namely, TSAI, TSSI, TSEI, EMEI, and 
OPI. Then options of expansions are defined in zones with highest values of OPI.

This paper is organized as follows. In section one, the mathematical formulation of the reference electricity market and the proposed methodologies are introduced. Section two applies the proposed methodologies on the two case studies. A 6 bus transmission system and modified IEEE 30 bus test system are used for presenting the effectiveness of the algorithms. Finally, conclusion remarks and future works close the paper.

\section{Mathematical Formulation of the Problem}

The first step in the expansion planning of transmission system is definition of the reference electricity market.

The National Electricity Market (NEM) is a whole sale market for the supply of electricity to retailers and end-users in Queensland (QLD), New South Wales (NSW), the Snowy, Victoria (VIC), South Australia (SA), and Tasmania (TAS).

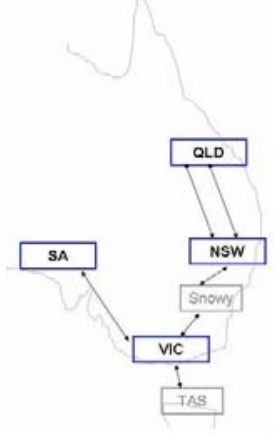

Figure 1 Australian Electricity Market Areas

National Electricity Market Management Company Limited (NEMMCO) manages the market and power system.

Generators offer to supply the market with specific amounts of electricity at particular prices with maximum offer of AUD10000 and then NEMMCO dispatches the forecasted load among the generators. NEM can be categorized as a single sided pool.

Figure 2 presents the mathematical modeling of the one sided pool applicable for NEM which is an improved model of [8].

The algorithm starts with the input data of the transmission system and electricity market. Transmission system data includes the normal data for load flow studies and electricity market data includes the bidding information of generators. Economic dispatch module dispatches the load among horizon year generators based on the ascending order of marginal cost [9]. The thermal limit of transmission lines are checked by the DC load flow module. If the optimal electricity market operating point can be supported by the existing transmission system then marginal transmission lines are searched. Marginal transmission line is defined as a line which is loaded right at its limit. In case of network thermal limit violation, the optimal power flow formulated through (1) is activated.
$\operatorname{Min} \sum_{i}^{N_{g}} M C_{g i} \times P_{g i}$

s.t.

$\bigcup_{j}^{N_{c}}\left\langle\sum_{i}^{N_{g}} G S F_{g i} \times P_{g i} \leq \overline{P_{l j}}-\left(P_{l j}^{0}-\sum_{i}^{N_{s}} G S F_{g i} \times P_{l j}^{0}\right)\right\rangle$

$\bigcup_{i}^{N_{s}}\left\langle P_{g i} \leq \overline{P_{g i}}\right\rangle$

$\sum_{i}^{N_{g}} P_{g i}=P_{d}$

Where in (1), $\mathrm{N}_{\mathrm{g}}$ is the number of generators, $\mathrm{MC}_{\mathrm{gi}}$ is the marginal cost of generator $\mathrm{i}, \mathrm{P}_{\mathrm{gi}}$ is the output active power of generator $\mathrm{i}, \mathrm{N}_{\mathrm{c}}$ is the number of congested transmission lines, $\mathrm{GSF}_{\mathrm{gi}}$ is the generator shift factor of generator i, $\overline{P_{l j}}$ and $\overline{P_{g i}}$ are the upper thermal limit of the line $\mathrm{j}$ and generator $\mathrm{i}$, respectively. $P_{l j}^{0}$ is defined as the active power flowing through transmission line $j . P_{d}$ is the total connected demand to the system.

Swing loop tries to find an optimum scenario of generation by which no line is overloaded for serving full connected load. In case of either cycling in swing loop or divergence of revised simplex method, the main loop tries to remove thermal violation of transmission lines through uniform load shedding. Given no network violation, marginal transmission lines are detected.

If the revised simplex method is not converged, then the main loop is activated. Main loop tries to find the optimum electricity market operation point which is supported by the transmission system through the uniform load shedding.

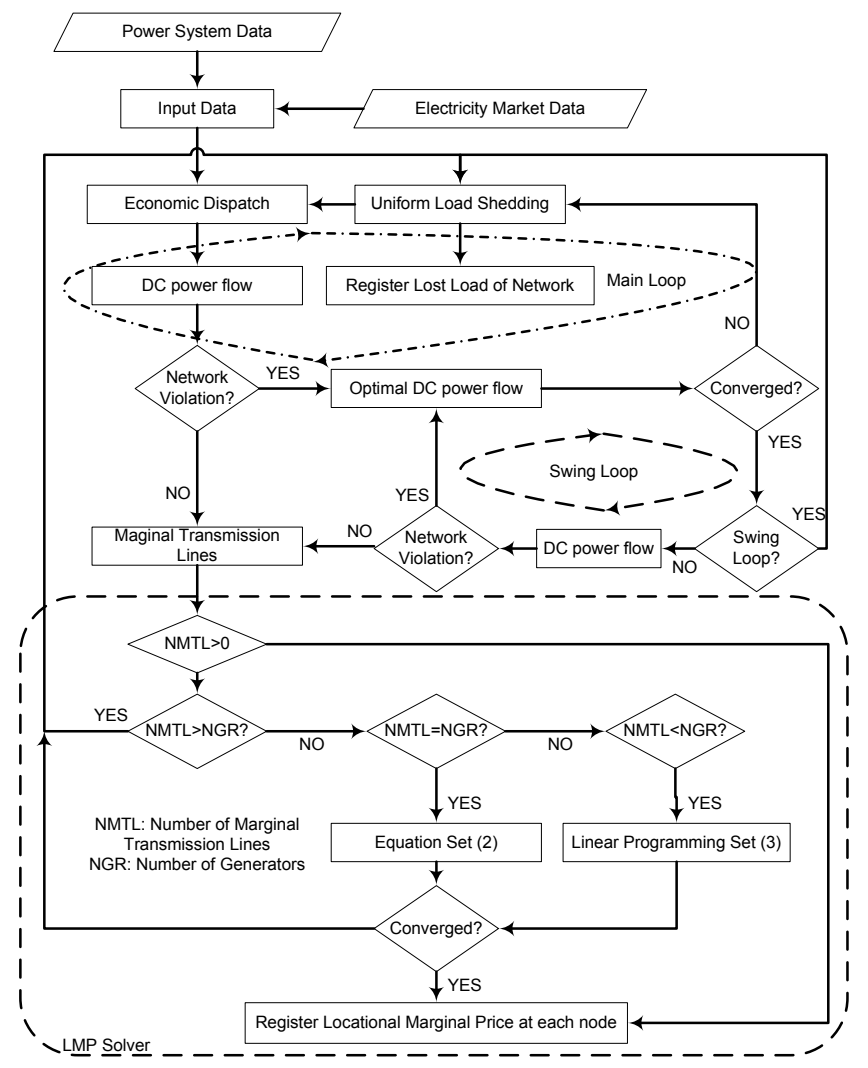

Figure 2 Mathematical modeling of the one sided pool electricity market 
If swing loop is successful, then the marginal transmission lines are detected else the main loop is activated.

Having detected all marginal transmission lines, the LMP solver is activated. If there is no binding transmission line, the power market will clear at the market clearing price else based on the number of marginal transmission lines (NMTL) and the number of generators (NGR) three algorithm would be used. If (NMTL>NGR) then uniform load shedding is employed else if (NMTL=NGR) then (2) would be solved.

$$
\begin{aligned}
& \bigcup_{j}^{N_{\text {IIt }}}\left\langle\sum_{i}^{N_{s}} G S F_{g i} \times \Delta P_{g i}=G S F_{g k}\right\rangle \\
& \sum_{i}^{N_{g}} \Delta P_{g i}=1 \\
& \text { Where } L M P_{k}=\sum_{i=1}^{N_{s}} M C_{g i} \times \Delta P_{g i}
\end{aligned}
$$

In case of (NMTL $<$ NGR), then the (3) will be solved by the revised simplex method.

$$
\begin{aligned}
& \operatorname{Min}\left(L M P_{k}=\sum_{i=1}^{N_{s}} M C_{g i} \times \Delta P_{g i}\right) \\
& \bigcup_{j}^{N_{u I r}}\left\langle\sum_{i}^{N_{g}} G S F_{g i} \times \Delta P_{g i}=G S F_{g k}\right\rangle \\
& \sum_{i}^{N_{g}} \Delta P_{g i}=1
\end{aligned}
$$

Equations (2) or (3) are solved at each connection point $\mathrm{k}$ to find the marginal price of electricity at that connection point. Algorithm presented through Figure 2, would be used as a sub-algorithm for finding the Value of Lost Load (VoLL) and Congestion Revenue (CR) considering a specific state of transmission system and electricity market.

To achieve a successful topology for transmission system in deregulated environments, it is necessary to define some criteria to measure the value of a specific expansion plan from view points of reliability, security, and operating efficiency of the transmission system as well as the economic efficiency of the electricity market.

The following sensitivity indices are used by this paper as the representatives of the major factors in evaluating transition of the transmission system using expansion options.

Reliability is an inherent characteristic and a specific measure of any component, device, or system which describes its ability to perform its intended function. In the context of the power systems, reliability in general terms is related to the degree of assurance in providing the customers with continuous service of satisfactory quality. The term "system reliability" can be grouped into two fundamental aspects of system adequacy and system security. Adequacy is associated with static conditions and does not include system disturbances. On the other hand, system security relates to the ability of the system to respond to disturbances arising within the system [10].

As a primary responsibility of the independent transmission company (ITC) in providing a reliable transmission system the following two sections introduce two sensitivity indices for evaluating of the expansion options of the transmission system from the angle point of adequacy and static security.
For the sake of mathematical formulation of the proposed indices, $\bar{X}$ and $\bar{Y}$ represent the state of transmission system and electricity market respectively. State of the transmission system is defined as the topology of transmission network and connection points of generators and loads along with the technical specification of these components. State of electricity market includes the biding strategy of generators in terms of their marginal production costs.

In this paper, a comprehensive index, Option performance Index (OPI) is defined to embrace the adequacy, security, and efficiency of transmission system along with the efficiency of the electricity market. This index is the weighted summation of the following indices.

\section{A. Transmission System Adequacy}

Adequacy of the transmission system can be evaluated based on the total load curtailment of the transmission system. As presented through Figure 2, the main loop is responsible for removing congestion from the system by firstly, redipatching of the committed generators and secondly, load shedding. Each time the shed load is registered and the Value of Lost Load (VoLL) is calculated. For demonstration purposes, the VoLL per MWh is considered as $\$ 1000$ which does not resemble those used in actual systems, such as $\$ 10$ 000/MWh for Australian NEM [11].

Transmission system adequacy Index, TSAI, can be expressed as equation (4),

$T S A I=-\left(\frac{\Delta \operatorname{VoLL}(\bar{X})}{\operatorname{VoLL}(\bar{X})} \times \frac{1}{\operatorname{INV}(\bar{X})}\right)^{\alpha}$

Where $\alpha$ is an odd empirical coefficient, $\bar{X}$ is the state of the transmission system, $\operatorname{VoLL}(\bar{X})$ is the Value of the Lost Load considering the $\bar{X}$ as the state of transmission system, and $\operatorname{INV}(\bar{X})$ is the value of investment to get the transmission system at the state of $\bar{X}$.

\section{B. Transmission System Static Security}

The first step in finding the static security of the transmission system is the contingency monitoring. Line outage distribution factor is used for contingency screening. If $A$ is defined as the set of severe single outages of the transmission system and B is defined as the set of all lines, then

$A=\left\{j \in B \mid P(j) \geq 0.8 P_{\text {Max }}(j)\right\}$

In (4), $\mathrm{j}$ is the line number and $\mathrm{P}(\mathrm{j})$ is the active power flowing through the line j. Finally, the Transmission System Static Security Index (TSSI) can be defined as (6),

$T S S I=-\left(\frac{\Delta S C I(\bar{X})}{S C I(\bar{X})} \times \frac{1}{\operatorname{INV}(\bar{X})}\right)^{\alpha}$

Where in (5), Security Contingency Index can be found through equation (7).

$$
\begin{aligned}
& \operatorname{SCI}(\bar{X})=\sum_{k} \omega_{k}\left(\sum_{j}\left(\frac{\left|P_{j}^{k}(\bar{X})\right|}{P_{j, \text { rating }}^{k}}\right)\right) \\
& \sum_{k} \omega_{k}=1 \quad \omega_{k} \geq 0
\end{aligned}
$$


In equation (7), $\left|\mathrm{P}_{\mathrm{j}}{ }^{\mathrm{k}}\right|$ is the absolute value of the power flowing through line $j$ given outage of line $k, P_{j, \max }{ }^{k}$ is the rating of line $\mathrm{j}$, and $\omega_{\mathrm{k}}$ is the severity index of the outage of transmission line $\mathrm{k}$ which is evaluated based on the power flowing through line $\mathrm{k}$ before outage. $\mathrm{j}$ is moving over those transmission lines that have the post outage power flow more than their rating limit. In this sense, the inner summation in (7) has a value more than 1. Based on the value of $\operatorname{SCI}(\bar{X})$ calculated through (7), (6) can find the influence of a specific expansion on overall security of the transmission system.

\section{Transmission System Operating Efficiency}

The operating efficiency of the transmission system can be evaluated through the Transmission System Operating Efficiency Index (TSEI) defined by (8).

$$
\begin{aligned}
& T S E I=\left(\frac{\Delta S U I(\bar{X})}{S U I(\bar{X})} \times \frac{1}{I N V(\bar{X})}\right)^{\alpha} \\
& \operatorname{SUI}(\bar{X})=\sum_{j}\left(\frac{\left|P_{j}(\bar{X})\right|}{P_{j, \text { rating }}}\right)
\end{aligned}
$$

$\left|P_{j}(\bar{X})\right|$ is the absolute value of the power flowing through transmission line $\mathrm{j}$ given the $\bar{X}$ state of the power system. System Usage Index $(\operatorname{SUI}(\bar{X}))$ is a value near to one with one as the best value. Having calculated $\operatorname{SUI}(\bar{X})$, the TSEI can evaluate the effects of a specific expansion option of the transmission system on the overall operating efficiency of the transmission system.

\section{D.Economic Efficiency of the Electricity Market}

The Independent System Operator collects more money from the load serving entities than pays to generator owners during the congestion period. It is the inherent nature of the LMP pricing method.

On the other hand, in a stable perfect competitive market, all producers offer their products at the same price and consumers have no restriction to buy from their favorite producers. Hence, in full competitive electricity market LMPs must be made equal and consequently, congestion revenue is very low.

Economic Efficiency Index of the Electricity Market, EMEI, can be evaluated based on the transmission system and electricity market states, $\bar{X}$ and $\bar{Y}$, through (9).

$$
\begin{aligned}
& E M E I=-\left(\frac{\Delta C R(\bar{X}, \bar{Y})}{C R(\bar{X}, \bar{Y})} \times \frac{1}{\operatorname{INV}(\bar{X})}\right)^{\alpha} \\
& C R(\bar{X}, \bar{Y})=\sum_{j}^{D} \lambda_{j} P_{d j}-\sum_{j}^{G} \lambda_{j} P_{g j}
\end{aligned}
$$

In (8), $P_{d j}$ is the active power that customer $d$ draws from the connection point $\mathrm{j}$ at marginal price of $\lambda_{j}$ and $\mathrm{P}_{\mathrm{gj}}$ is the active power that producer $g$ inject to the connection point $\mathrm{j}$ at marginal price of $\lambda_{j}$.

The effect of expansion options on the electricity market can be evaluated by the (9).

\section{E. Transmission System Expansion Cost}

The function $\operatorname{INV}(\bar{X})$ considers the expansion cost of state $\bar{X}$ of the transmission system in all aforementioned indices. This cost embraces the construction, maintenance, and environmental costs.

Finally, the performance of each expansion option is evaluated based on the Option Performance Index (OPI) defined in (10).

$$
\begin{aligned}
& \operatorname{OPI}(\bar{X}, \bar{Y})=\mathrm{W}_{1} \times \operatorname{TSAI}(\bar{X})+\mathrm{W}_{2} \times \operatorname{TSSI}(\bar{X})+\mathrm{W}_{3} \times \operatorname{TSEI}(\bar{X}) \\
& +\mathrm{W}_{4} \times \operatorname{EMEI}(\bar{X}, \bar{Y})
\end{aligned}
$$

Where $\mathrm{w}$ is the empirical weighting factor of each criterion. According to the principle of the optimality introduced by Bellman and Dreyfus, a policy is optimal if at a stated stage, whatever the preceding decisions may have been, the decisions still to be taken constitute an optimal policy when the result of the previous decision is included.

The heuristic approaches can effectively search the quasi optimal solution in problems in which the systematic exploration of all the options is too cumbersome. Apply the theory of Bellman, the optimum state of the transmission system is calculated through a step-by-step adding or removing lines methodologies introduced in the following sections.

\section{- $\quad$ Adding Line Methodology}

The general framework for this method has been presented through Figure 3.

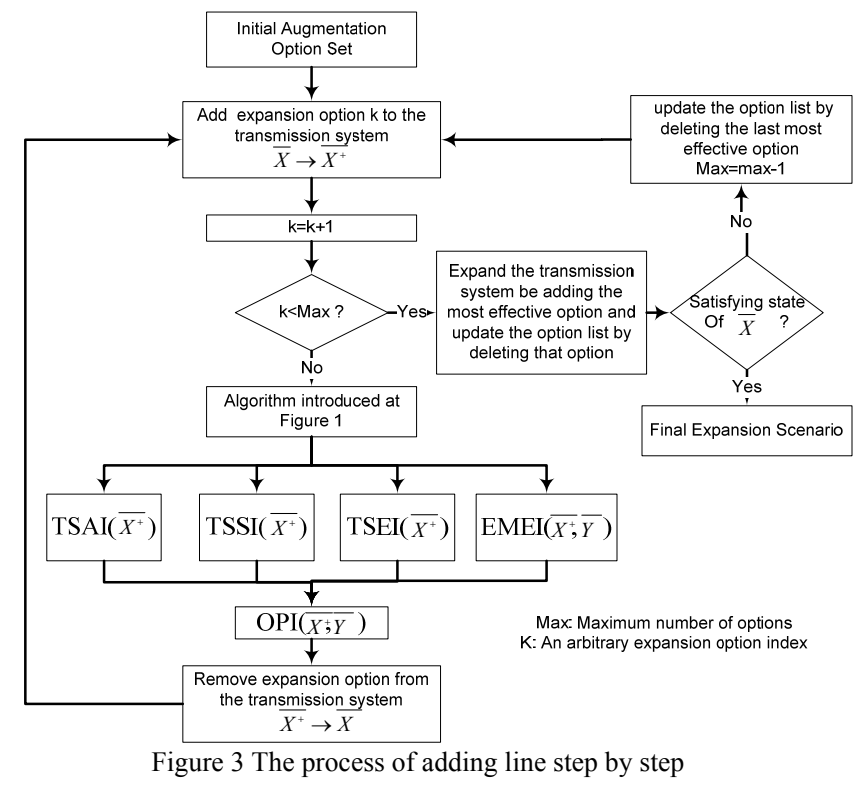

As presented through Figure 3, the algorithm starts with the initial options of transmission expansion. It evaluates each option by its comprehensive sensitivity based performance index and then selects the most effective option as the one with highest value for option performance index. This option is added to the transmission system and deleted from the list 
of options. This process is continued until a satisfying state for transmission system is found.

\section{- Removing Line Methodology}

The process for second strategy of expansion is shown in Figure 4. The algorithm starts with addition of all available transmission options to the existing transmission system. At this step each option is removed from the system and the option is scored by the option performance index (OPI). As OPI measure the next state of transmission system and electricity market based on a multi criteria view, the option that improves the performance of the system given its removal would be removed. In this way, in each state of transmission system and electricity market, the algorithm locates the highest overall performance for the network.

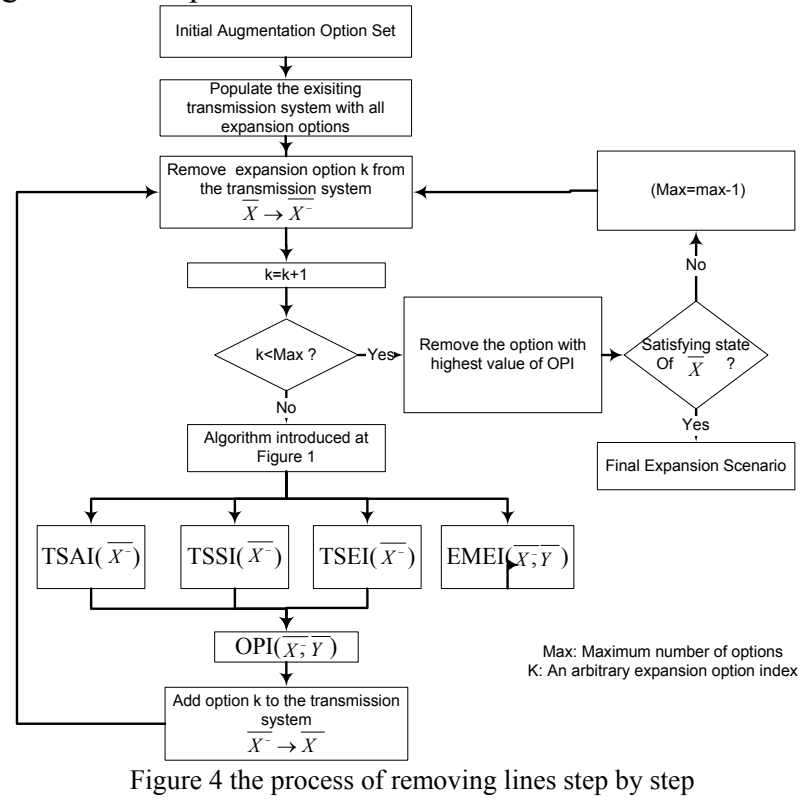

The next section is involved with the application of the proposed frameworks on two case studies, namely a 6 bus transmission system and a modified IEEE 30 bus test system.

\section{NUMERICAL STUDIES}

The presented approach is applied to a 6 bus test system [9]. Figure 5 shows the single line diagram of the 6 bus transmission system.

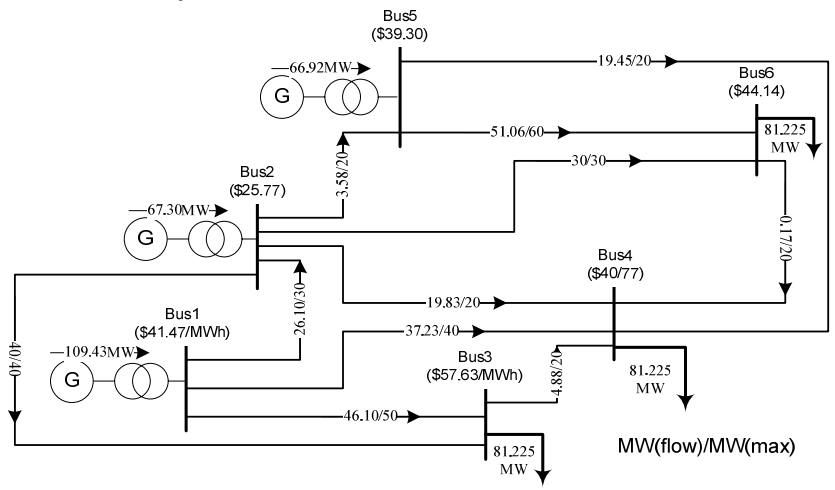

Figure 5 Single line diagram of the 6 bus test system (state of the system before expansion)
The initial state of the system has $\$ 267566.8 / \mathrm{h}$ as the congestion revenue of the system, $\$ 125090.3 / \mathrm{h}$ as the value of lost load, 1.1033 p.u. as the contingency index, and finally 0.7244 p.u. as the transmission usage index. $\$ 41.51 / \mathrm{MWh}$ is the average of the LMP with $\$ 9.31 / \mathrm{MWh}$ as the standard deviation.

Applying the introduced set of indices to the expansion options of the transmission system, TEII, TSAI, TSSI, and EMEI calculated in the adding line methodology are shown through Figures 6 to 7 respectively.

Based on the found sensitivity indices, option 10 which associate with building of one transmission line between nodes 3 and 4, has the highest effect on the overall performance index of the transmission system. The Algorithm selects the option 10 and add it to the existing transmission system.

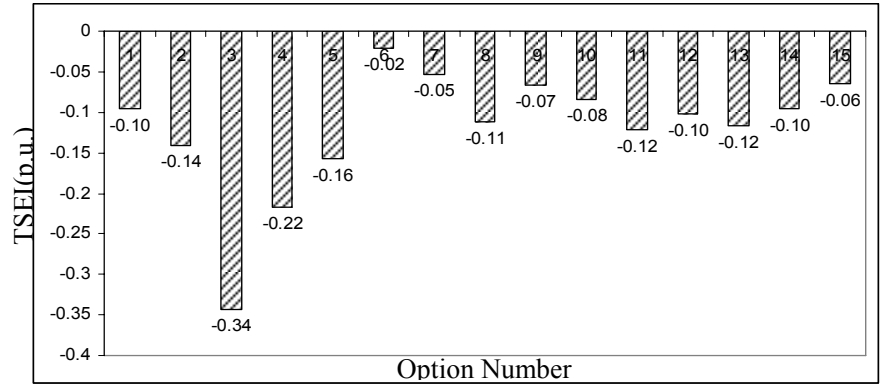

Figure 6 TSEI in p.u. versus 15 expansion options of the transmission system

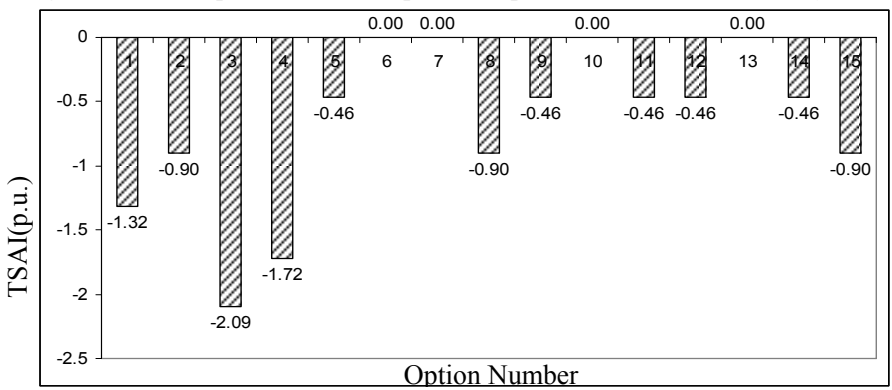

Figure 7 TSAI in p.u. versus 15 expansion option of the transmission system

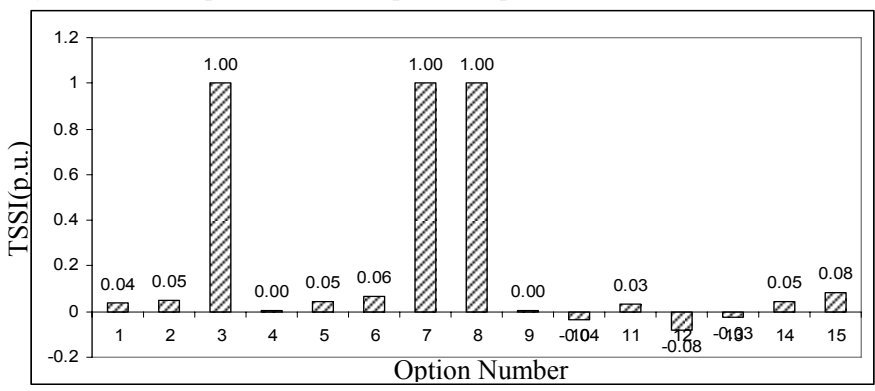

Figure 8 TSSI in p.u. versus 15 expansion option of the transmission system

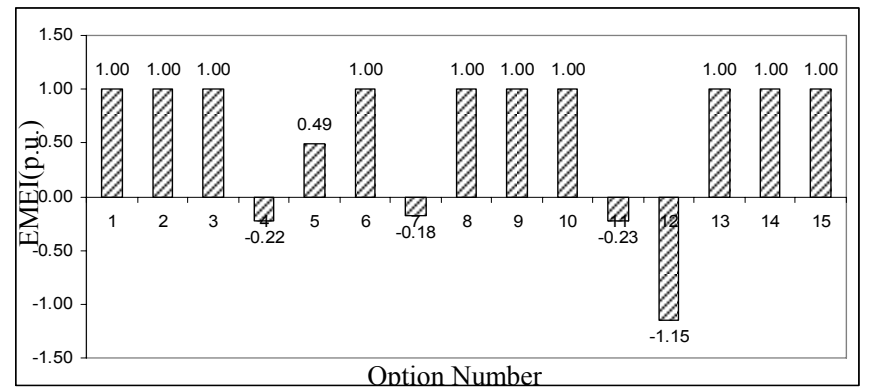

Figure 9 EMEI in p.u. versus 15 expansion options of the transmission system 
Based on the found sensitivity indices, a new transmission line between nodes 3 and 4 , has the highest effect on the overall performance index of the transmission system. The adding line methodology locates the quasi optimal state of the future transmission system in three iterations.

TABLE 1 SELECTED TRANSMISSION LiNES FOR AUgMENTATION THROUGH ADDEING AND REMOVING METHODOLOGIES(6 BUS TEST SYSTEM)

\begin{tabular}{|c|c|c|c|c|c|}
\hline No. & From & To & X(p.u.) & $\begin{array}{l}\text { Max Thermal } \\
\text { Capacity(p.u.) }\end{array}$ & $\begin{array}{l}\text { Cost } \\
\text { (p.u.) }\end{array}$ \\
\hline \multicolumn{6}{|c|}{ Adding Scheme } \\
\hline & & & & & \\
\hline 1 & 3 & 4 & 0.18 & 0.28 & 130.00 \\
\hline 2 & 3 & 5 & 0.18 & 0.28 & 135.00 \\
\hline 3 & 1 & 6 & 0.18 & 0.58 & 130.00 \\
\hline \multicolumn{6}{|c|}{ Removing Scheme } \\
\hline 1 & 1 & 2 & 0.10 & 0.40 & 200.00 \\
\hline 2 & 1 & 3 & 0.14 & 0.35 & 150.00 \\
\hline 3 & 1 & 4 & 0.12 & 0.38 & 160.00 \\
\hline 4 & 2 & 5 & 0.10 & 0.45 & 250.00 \\
\hline 5 & 3 & 5 & 0.18 & 0.28 & 135.00 \\
\hline
\end{tabular}

In case of 6 bus test system, at the final state of the transmission system, congestion revenue and value of lost load are zero. 1.13 p.u. and 0.63 p.u. are reported as the SCI and SUI. The price of electricity at each connection point is \$41.47/MWh.

On the other hand, the removing scheme designs the horizon year transmission system by addition of options 1-2, 1-3, 1-4, $2-5$, and 3-5. The final state of transmission system and electricity market settles on zero as congestion revenue and value of lost load, 1.24 p.u. as the SCI and 0.53 p.u. as the SUI. The price of electricity at each connection point is \$41.47/MWh with 270MW load served.

As the final approval of the proposed methods, a modified 30 bus IEEE test system is used. The load of system is selcted as the $50 \%$ of the case study introduced in [5] to model a short term environment for the evaluation of the system.

The initial state of the transmission system is presented through Figure .

Applying the proposed algorithm in Figure 2, the optimal state of the electricity market supported by the existing transmission system has been shown in Figure. The transmission system can support the electricity market with $\$ 13.55 / \mathrm{MWh}$ as the average of the locational marginal price and $\$ 2.68 / \mathrm{MWh}$ as the standard deviation of the LMP. $367.55 \mathrm{MW}$ is the total served load by the transmission system which corresponds to $73.50 \%$ of the forecasted load on the horizon year.

Transmission Lines between B1-B3, B9-B10, B16-B17, and $\mathrm{B} 5-\mathrm{B} 30$ are marginal transmission lines which are loaded right at their limits.

The proposed adding line methodology along with set of indices can locate the most effective lines in 4 iterations.

By Comparison, the state of the transmission system and electricity market has been improved significantly by addition of each option.

Finally, Figure 6, shows the location of the new transmission lines by two introduced methodologies.

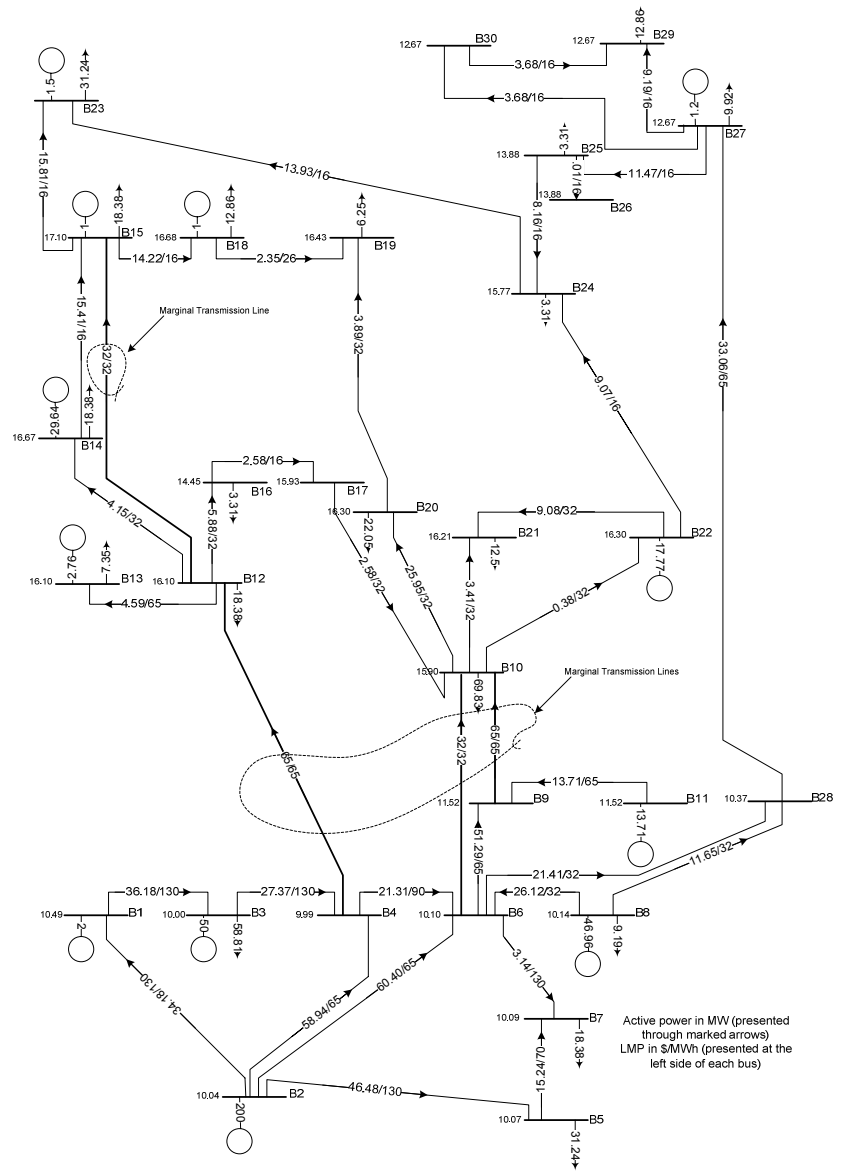

Figure 5 Single line diagram of the modified IEEE 30 bus test system (state of the system before expansion)

In the case of modified IEEE 30 bus test system, the final selected options are tabulated through Table 2.

TABLE 2 PRESENTS THE FINAL SELECTED TRANSMISSION LINES FOR HORIZON YEAR TRANSMISSION SYSTEM IN CASE OF MODIFIED IEEE 30BUS TEST SYSTEM.

\begin{tabular}{|c|c|c|c|c|c|}
\hline No. & From & To & X(p.u.) & $\begin{array}{c}\text { Max Thermal } \\
\text { Capacity(p.u.) }\end{array}$ & $\begin{array}{c}\text { Cost } \\
\text { (p.u.) }\end{array}$ \\
\hline \multicolumn{7}{|c|}{ Adding Scheme } \\
\hline 1 & 1 & 3 & 0.21 & 1.3 & 1 \\
\hline 2 & 9 & 10 & 0.21 & 1.3 & 1 \\
\hline 3 & 16 & 17 & 0.21 & 1.3 & 1 \\
\hline 4 & 5 & 30 & 0.21 & 1.3 & 1 \\
\hline \multicolumn{7}{|c|}{ Removing Scheme } \\
\hline 1 & 23 & 25 & 0.21 & 1.3 & 1 \\
\hline 2 & 22 & 30 & 0.21 & 1.3 & 1 \\
\hline 3 & 12 & 15 & 0.21 & 1.3 & 1 \\
\hline 4 & 19 & 22 & 0.21 & 1.3 & 1 \\
\hline 5 & 28 & 27 & 0.21 & 1.3 & 1 \\
\hline 6 & 2 & 26 & 0.21 & 1.3 & 1 \\
\hline 7 & 22 & 26 & 0.21 & 1.3 & 1 \\
\hline 8 & 4 & 6 & 0.21 & 1.3 & 1 \\
\hline 9 & 2 & 5 & 0.21 & 1.3 & 1 \\
\hline 10 & 1 & 30 & 0.21 & 1.3 & 1 \\
\hline
\end{tabular}

The removing strategy locate the transmission lines $23-25,22-$ $30,12-15,19-20,28-27,2-26,22-26,4-6,2-5$, and 1-30 in the horizon year transmission system. The final state of transmission system and electricity market is as follows.

System does not have any marginal transmission line and so the price of electricity at all transmission connection points is 
$\$ 22 / \mathrm{MWh}$. The congestion revenue of the system is zero with $42.21 \%$ and $106.72 \%$ reported as the SUI and SCI in the removing methodology. Similarly, $44.47 \%$ and $124.46 \%$ are SUI and SCI for the final state of transmission system using adding methodology.

In both cases, all transmission lines are loaded under their thermal limit and total connected load of 500MW is served.

The overall performance of the final state of transmission system obtained from the both methodologies is almost the same but with different topologies.

This stems from the inherent nature of the adding and removing methods. Since all the methodologies that we proposed just can find the quasi-optimal results, using different methods, we find different quasi-optimal results.

At last, although the proposed frameworks for expansion planning of the transmission system are promising enough in finding the quasi-optimal location of the future transmission lines considering transmission system reliability and electricity market efficiency, the sensitive zone detection can be mentioned as another application of the proposed methodologies. Since the introduced indices namely, TSAI, TSSI, TSEI, and EMEI are proposed base on the value of each transition of transmission system from one state to another, they can be used for finding the most sensitive areas of the planning. Having saved the OPI for the best options through the running of the adding or removing framework, the area of the transmission system can be divided into different zones based on the value of each zone for expansion planning.

This method would be very useful for smart reduction of search space in large scale power systems and locating the new transmission lines in a more effective way.

\section{CONCLUSIONS AND FUTURE RESEARCH}

Transmission planning is a key issue in evaluating the smooth function of power system both from the point of view of reliability and economic efficiency.

Transmission system adequacy and security can be classified as the reliability aspects while electricity market efficiency, and investment costs fall in the economic efficiency category.

The competitive context demands new tools for market transmission planning that needs to incorporate the bidding behavior of producers. Minimization of the investment cost should link with maximization of the overall transmission system performance. The approaches introduced accommodate the (1) security of the transmission system in case of single outages (2) Adequacy of the transmission system (3) a perfect stable electricity market (4) investment cost and (5) operation efficiency of transmission system in terms of transmission usage in its final multi criteria decision making in its multi criteria decision making. Sensitivity analysis and dynamic programming are used for systematic approach to the quasi-optimal solution.

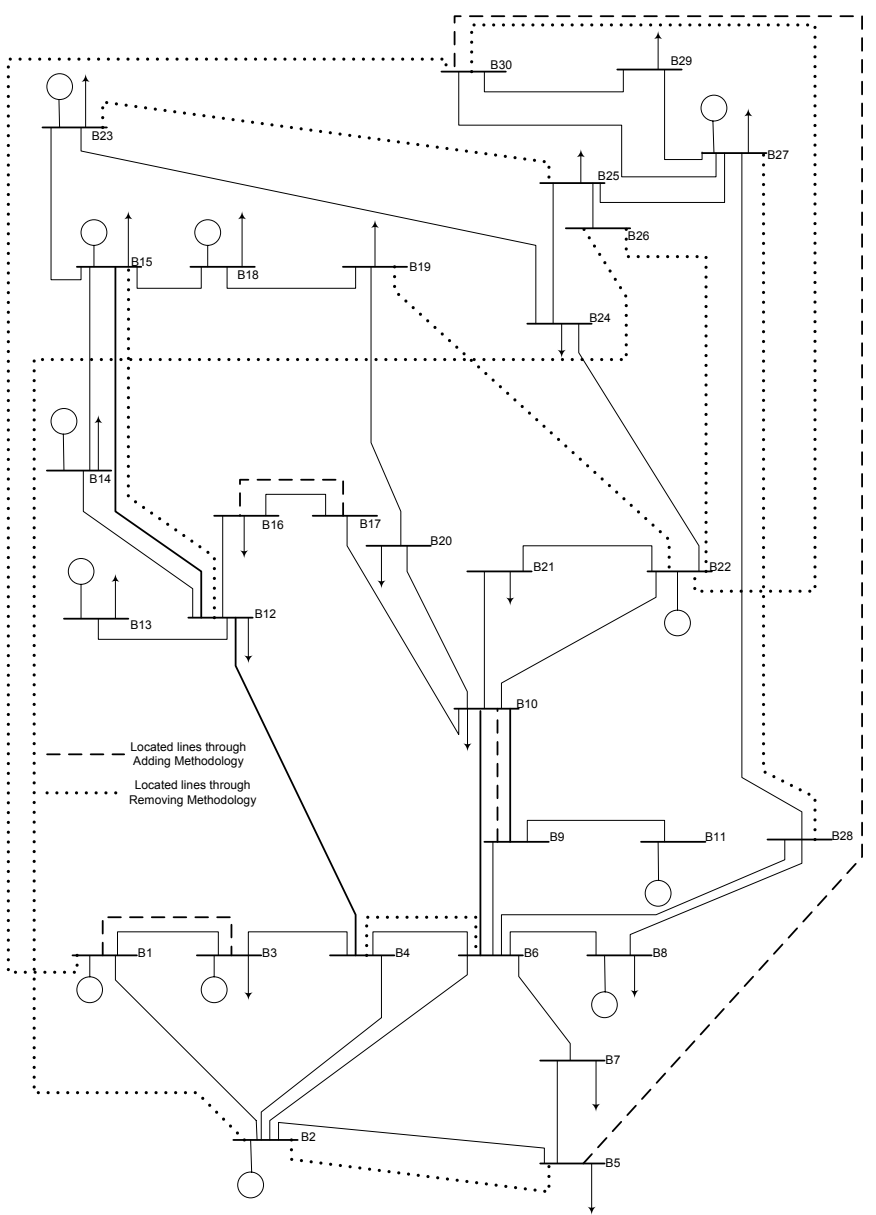

Figure 6 Single line diagram of the modified IEEE 30 bus test system (state of the system after expansion using both adding and removing line methodology)

Using the case studies, the algorithms would be effective in providing direction for transmission planning in a competitive electricity market especially in addressing smart options for large scale power systems. The authors currently are working on applying of the proposed framework for expansion planning of Queensland Transmission System, Australia, as well as identifying sensitive zones in the Queensland Transmission System.

\section{REFERENCE}

[1] "Annual Planning Report 2007" published by Queensland Electricity Transmission Corporation Limited, Powerlink Queensland

[2] California Independent System Oprtator, "Transmission Economic Assessment Methodology (TEAM)", June 2006

[3] G. Latorre, R. D. Cruz, J. M. Aleiza, and A. Villegas, "Classification of Publications and Models on Transmission Expansion Planning",IEEE Transaction on Power Systems, Vol. 18, No.2, May 2003, pp 938-946

[4] F.F. Wu, F.L. Zheng, F.S. Wen, "Transmission Investment and Expansion Planning in a Restructured Electricity Market", Science Direct, Energy 31 2006 954-966

[5] Majid Oloom Buygi, Gerd Balzer, Hassan Modir Shanechi, and Mohammad Shahidehpour, "Market-Based Transmission System Planning", IEEE Transactions on Power Systems, Vol.19, No.4, November 2004

[6] J. Choi, A. Keib, and T. Tran "A Fuzzy Branch and Bound-Based Transmission System Expansion Planning for the Highest Satisfaction Level of 
the Decision Maker" IEEE Transactions on Power Sytems, Vol. 20, No.1, February 2005, pp. 476-484

[6] CIGRE Task Force C5.2.1 and B. Luiz Augusto Barroso(PSR/Mercados de Energia, Teofilo H. Cavalcanti(CHESF- The Sao Francisco Hydro-Electric Company, Brazil), Paul Giesbertz(DTe, The Netherland), Konrad Purchala(K.U. Leuven, Belgium), "Classification of electricity market models worldwide," 2005.

[7] H. Wang, P. Rastgoufard "Power System Locational Marginal Pricing in Deregulated Market" Phd Thesis, Tulan university, November 2003

[8] A.J. Wood, B.F. Wollenberg, "Power Generation, Operation, and Control", John Wiely\&Sons, Second Edition

[10] R. Billinton, R.N. Allan, "Reliability Evaluation of Power Systems", Plenum Press, New York, 1984

[11] National Electricity Market Management Company Website

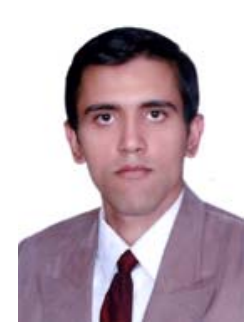

Mohammad R. Hesamzadeh graduated from Shiraz University in 2002 with a Bachelor of Engineering Degree and received a Master of Engineering Degree in power systems from Tarbiat Modarres University in 2004. Currently, he is with Central Queensland University as a Senior Researcher while pursuing his Ph.D. studies. His special fields of interest include mathematical and statistical modeling and analyzing of power systems, and intelligent system applications in engineering. He is a student member of IEEE and a Professional Engineer in Australia.

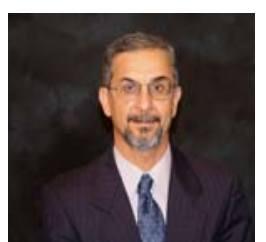

Nasser Hosseinzadeh (M'86) was born in Iran in 1960. He graduated from Shiraz University in 1986 with a Bachelor of Science degree in Electrical and Electronics Engineering. He subsequently received a Master of Science degree from Iran University of Science and Technology in 1992 and a PhD degree in Electrical Engineering from Victoria University in Australia in 1998. He worked at an Engineering Research Center in the periods of 1986-1990 and 1992-1994. He is currently the Head of Department of Systems at the Faculty of Sciences, Engineering and Health at Central Queensland University, Rockhampton, Australia. His special fields of interest include power system analysis and planning, power system stability, intelligent system applications in engineering, distributed generation and rural energy supply.

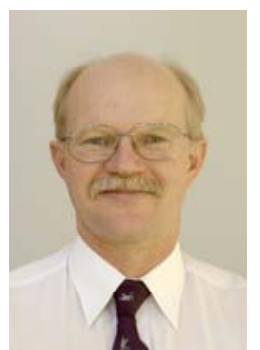

Peter Wolfs (M'80, SM'99) was born in Rockhampton Australia in 1959. He graduated from the Capricornia Institute of Advanced Education in 1980 with a Bachelor of Engineering Degree. He subsequently secured a Master of Engineering degree with the Philips International Institute in the Netherlands in 1981 and a $\mathrm{PhD}$ degree at the University of Queensland in 1992.

$\mathrm{He}$ is the Associate Dean (Research and Innovation) at the Faculty of Sciences, Engineering and Health at Central Queensland University. His special fields of interest include rural and renewable energy supply, electric, solar and hybrid electric vehicles and intelligent systems applications. Professor Wolfs is Senior Member of IEEE, a Fellow of Engineers Australia, a Registered Professional Engineer in the State of Queensland and a member of the Railway Technical Society of Australia. He is the author of more than 120 technical journal and conference publications in electrical engineering. 